\title{
TEM Study of the Selectivity of Crystallographic Variants of the Orientation Relationships of Cementite in an Aged Low-Carbon Martensitic Steel
}

\author{
S.V. Prikhodko ${ }^{*}$, A.S. Prudnikov ${ }^{* *}$, R.V. Televich ${ }^{* *}$, \\ *Materials Science and Engineering Dept., UCLA, Los Angeles, CA, 90095 \\ **Institute for Metal Physics NASU, 36 Vernadsky Str., Kyiv-03142, Ukraine
}

The decomposition of martensite in plain carbon steels during aging produces cementite crystals $\left(\mathrm{Fe}_{3} \mathrm{C}\right)$ of only 2 or 3 out of the 24 possible variants of different Orientation Relationships (ORs) [1-4]. It is believed that the quasi-ordered dislocation structure or the twinned structure in the martensite that occur after the $\gamma \rightarrow \alpha$ transformation is responsible for this selectivity of the variants of the OR. At present there are not enough data to formulate a selectivity law with a high degree of certainty.

The $\gamma \rightarrow \alpha$ transformation in a single crystal of austenite gives 24 crystallographically equivalent variants of martensite according to the Kurdumov-Sachs or Greninger-Troiano OR. Decreasing the number of possible variants would significantly simplify the crystallographic analysis of the cementite-martensite OR during tempering. A plain-carbon steel $(\mathrm{Fe}-0.4 \mathrm{wt} . \% \mathrm{C})$ in which the structure of martensite is lath like was chosen for this study. The crystals of lath martensite are grouped into big packets, where only six different variants of orientations of martensite occur with their $\{011\}_{\alpha}$ planes parallel to only one of the possible four $\{111\}_{\gamma}$. Additionally, the cementite crystals, in that martensite are oriented either by the Isaichev (I) OR or the Bagaryatskii (B) OR, which differ only slightly [3]. Specimens with the lath-martensitic structure (packets up to $10 \mathrm{~mm}$ ) were obtained by quenching large-grained austenite crystals produced by recrystallization of hot rolled bulk specimens after annealing at $1250{ }^{\circ} \mathrm{C}$ for 10 hours. The specimens were aged at $600{ }^{\circ} \mathrm{C}$ followed by immediate quenching. Heating to the aging temperature was fast $\left(50{ }^{\circ} \mathrm{Cs}^{-1}\right)$ to prevent excessive cementite growth. TEM foils were prepared by standard techniques. Electron microscopy and micro-diffraction were done using a JEOL JEM-2000FX operating at $200 \mathrm{kV}$.

It was shown that the $\mathrm{OR}$ between the $\mathrm{Fe}_{3} \mathrm{C}$ crystals and lath martensite was either I or B. Fig. 1 shows a typical micro-diffraction pattern (a) as well as its indexing (b). Since the I and B ORs are close to each other, micro-diffraction did not allow us to distinguish them with confidence. We chose to use the I OR notation on the basis of its simplicity. The 24 variants of the I OR form 12 pairs of $\mathrm{Fe}_{3} \mathrm{C}$ orientations which differ by only a small rotation angle $\left(\sim 6^{\circ}\right)$ around a common $[010]_{\mathrm{Fe}_{3} \mathrm{C}}$ axis. That is why variants within such pairs are also indistinguishable. 43 cementite crystals from 7 different crystals of martensite were successfully identified. Each martensite crystal created one or two variants of $\mathrm{Fe}_{3} \mathrm{C}$, and the variants differed from one crystal to another. The normalized distribution of the $\mathrm{Fe}_{3} \mathrm{C}$ crystals, identified by their variants of the I OR, is shown in Fig.2; the variants are presented in Table 1. The variants are not distributed uniformly. Some variants are clearly more evident than others and some variants are completely absent. Better statistics and accuracy of the identification of the variants would be required. In a similar study [4] done on twinned martensite ( 8 cementite crystals were analyzed), it was shown that the variants of $\mathrm{Fe}_{3} \mathrm{C}$ that have an angle of $\sim 66^{\circ}$ between the $[001]_{\mathrm{Fe} 3 \mathrm{C}}$ and the tetragonal axis of the martensite were the only possible ones. Analysis of the variants of the OR (Table 1) that satisfy the condition of Ikonnikov et al. [4], shows that variants 5-8, 13-16 would be suppressed. It follows that the suggested selectivity law [4] is not universal and that the structure of the martensite (lath or 
twinned) could be a critical that governs the variant selection law. On the other hand we believe that the statistics in the study of Ikonnikov et al. [4] were not quite good enough to justify their conclusions.

[1] E. Tekin, B.M. Kelly, Precipitation from iron-based alloys, Cordon \& Breach Sci. Publ., London (1965)

[2] Y. Omori, A. Davenport, R. Honeycombe, Trans ISI Japan 4 (1972) 112

[3] R.V. Televich et al., Metallofizika i Noveishie Tehnologii 1 (1994) 62

[4] V.V. Ikonnikov et al., Izvestia Akademii Nauk SSSR, Physics, 7 (1974) 1452

[5] Authors acknowledge Professor A.J. Ardell (UCLA, Dept. of Mat. Sci.) for his critical comments regarding to the content of the paper.
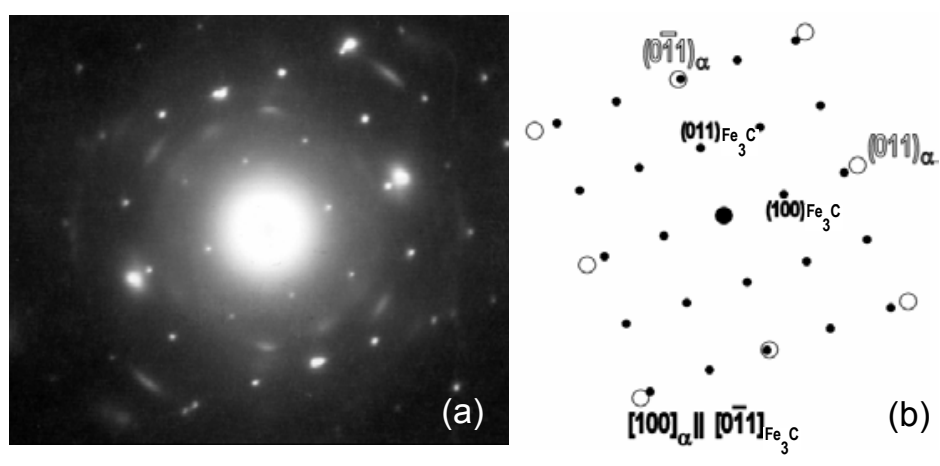

Fig. 1. Typical micro diffraction pattern from cementite within a martensite crystal in the $\mathrm{Fe}-0.4 \mathrm{wt} . \% \mathrm{C}$ steel after aging (a) and result of the indexing (b).

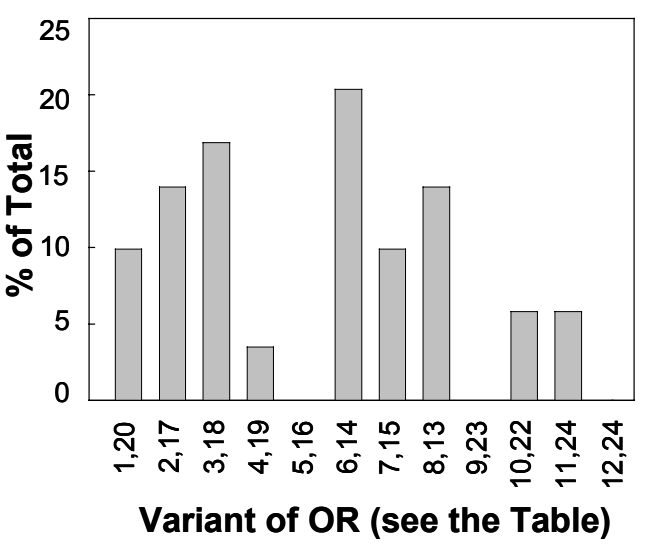

Fig.2. Normalized distribution of $\mathrm{Fe}_{3} \mathrm{C}$ crystals by variants of the I OR

Table 1. Variants of the Isaichev OR between martensite and cementite.

\begin{tabular}{|c|c|c|c|c|c|}
\hline № & \multicolumn{2}{|c|}{ Variant of the OR } & № & \multicolumn{2}{|c|}{ Variant of the OR } \\
\hline 1 & ${ }^{(103)} \mathrm{Fe} 3 C^{\|(011)} \alpha$ & ${ }^{[010]_{F e} 3 C} \|[1 \overline{1} 1]_{\alpha}$ & 13 & ${ }^{(103)} \mathrm{Fe} 3 C^{\|(101)} \alpha$ & ${ }^{[010]}{ }_{F e 3 C} \|[11 \overline{1}]_{\alpha}$ \\
\hline 2 & ${ }^{(103)_{F e} 3 C^{\|(0 \overline{1} \overline{1})} \alpha}$ & ${ }^{[010]_{F e 3 C}} \|[11 \overline{1}]_{\alpha}$ & 14 & ${ }^{(103)_{F e} 3 C} \|(\overline{1} 0 \overline{1})_{\alpha}$ & ${ }^{[010]_{F e} 3 C} \|\left[{ }^{[1} 11\right]_{\alpha}$ \\
\hline 3 & 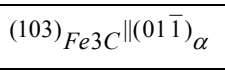 & {$\left[{ }^{[010]_{F e 3 C}} \|[\overline{1} \overline{1} \overline{1}]_{\alpha}\right.$} & 15 & ${ }^{(103)}{ }_{F e 3 C} C^{\|(10 \overline{1})} \alpha$ & ${ }^{[010]_{F e} 3 C} \|[1 \overline{1} 1]_{\alpha}$ \\
\hline 4 & ${ }^{(103)_{F e} 3 C^{\|(0 \overline{1} 1)} \alpha}$ & {$\left[^{[010]_{F e} 3 C} \|[\overline{1} 11]_{\alpha}\right.$} & 16 & ${ }^{(103)}{ }_{F e 3 C} C^{\|(\overline{1} 01)} \alpha$ & ${ }^{[010]_{F e} 3 C} \|[\overline{1} \overline{1} \overline{1}]_{\alpha}$ \\
\hline 5 & ${ }^{(103)} \mathrm{Fe} 3 C^{\|(01 \overline{1})} \alpha$ & ${ }^{[010]^{F e} 3 \mathrm{C}} \|{ }^{[111]_{\alpha}}$ & 17 & ${ }^{(103)_{F e} C \|(\overline{1} 10)_{\alpha}}$ & ${ }^{[010]_{F e} 3 C} \|[\overline{1} \overline{1} 1]_{\alpha}$ \\
\hline 6 & ${ }^{(103)} \mathrm{Fe} 3 C^{\|(0 \overline{1} 1)} \alpha$ & ${ }^{[010]_{F e} 3 C} \|[1 \overline{1} \overline{1}]_{\alpha}$ & 18 & ${ }^{(103)} \mathrm{Fe} 3 C^{\|(1 \overline{1} 0)} \alpha$ & ${ }^{[010]^{F e} 3 \mathrm{C}} \|\left[{ }^{[111]_{\alpha}}\right.$ \\
\hline 7 & ${ }^{(103)} F e 3 C^{\|(011)} \alpha$ & ${ }^{[010]_{F e} 3 C} \|[\overline{1} 1 \overline{1}]_{\alpha}$ & 19 & ${ }^{(103)}{ }_{\mathrm{Fe}} 3 C^{\|(110)} \alpha$ & ${ }^{[010]_{F e} 3 C} \|[1 \overline{1} \overline{1}]_{\alpha}$ \\
\hline 8 & ${ }^{\left.(103)_{F e} 3 C^{\|(0 \overline{1} \overline{1}}\right)_{\alpha}}$ & ${ }^{[010]_{F e} 3 C} \|\left[{ }^{[1} \overline{1} 1\right]_{\alpha}$ & 20 & $\left.{ }^{(103)}{ }_{F e 3 C} C^{\|(\overline{1}} \overline{1} 0\right) \alpha$ & ${ }^{[010]_{F e 3 C}} \|[\overline{1} 1 \overline{1}]_{\alpha}$ \\
\hline 9 & ${ }^{(103)_{F e 3 C} \|(\overline{1} 01)} \alpha$ & ${ }^{[010]^{F e} 3 \mathrm{C}} \|\left[{ }^{[111]_{\alpha}}\right.$ & 21 & ${ }^{(103)} \mathrm{Fe} 3 C^{\|(110)} \alpha$ & ${ }^{[010]_{F e} 3 C} \|\left[{ }^{1} 11\right]_{\alpha}$ \\
\hline 10 & ${ }^{(103)} \mathrm{Fe} 3 C^{\|(10 \overline{1})} \alpha$ & 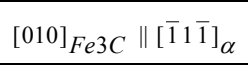 & 22 & ${ }^{(103)}{ }_{F e} 3 C^{\|(\overline{1} \overline{1} 0)} \alpha$ & ${ }^{[010]_{F e} 3 C} \|[1 \overline{1} 1]_{\alpha}$ \\
\hline 11 & ${ }^{(103)} \mathrm{Fe}_{3} \mathrm{C}^{\|(101)} \alpha$ & ${ }^{[010]_{F e} 3 C} \|\left[{ }^{[1} \overline{1} 1\right]_{\alpha}$ & 23 & ${ }^{(103)} \mathrm{Fe} 3 C^{\|(1 \overline{1} 0)} \alpha$ & ${ }^{[010]_{F e 3 C}} \|\left[{ }^{[\overline{1}} \overline{1} \overline{1}\right]_{\alpha}$ \\
\hline 12 & $(103)_{\mathrm{Fe} 3 \mathrm{C}} \|(\overline{1} 0 \overline{1})_{\alpha}$ & ${ }^{[010]} \mathrm{Fe} 3 \mathrm{C} \|[1 \overline{1} \overline{1}]_{\alpha}$ & 24 & ${ }^{(103)} \mathrm{Fe} 3 C^{\|(\overline{1} 10)} \alpha$ & ${ }^{[010]_{F e} 3 \mathrm{C}} \|[11 \overline{1}]_{\alpha}$ \\
\hline
\end{tabular}

